\section{N. Siafakas ${ }^{1}$}

M. Fletcher ${ }^{2}$

K-H. Carlsen ${ }^{3}$

${ }^{1}$ ERS Past President, Heraklion, Greece

${ }^{2} E L F$ Chair, Warwick, UK

${ }^{3}$ ELF Past Chair, Oslo, Norway

\title{
747,000 litres air blown to help raise awareness of spirometry
}

The first ever World Spirometry Day took place on October 14, 2010, and "blew" expectations out of the water. Results recorded on the day itself and up to 1 week afterwards reached $>83,000$ tests from $>250$ events. However, the numbers are set to continue rising, as many events are ongoing for the month of October and through to World COPD Day on November 17, 2010, and 400 events are yet to share their results. These early indications show how the day has captured the interest and enthusiasm of people across the globe, and what an impact it has had on the profile of spirometry testing and lung health.

\section{A truly global effort}

World Spirometry Day (WSD) was organised as part of the Year of the Lung, the initiative from FIRS (Forum of International Respiratory Societies), and was supported in all continents by its members (right). The Year of the Lung aims to raise awareness about lung health among the public, initiate action in communities worldwide, and advocate for resources to combat lung disease including increased

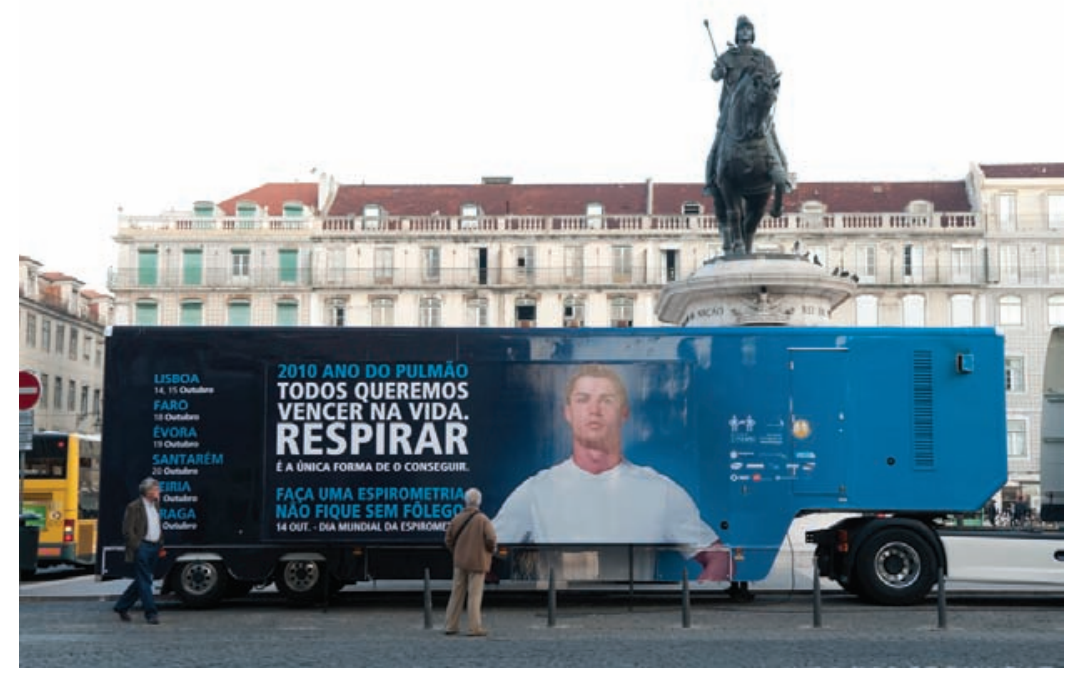

Portuguese WSD campaign
FIRS member organisations

- Asociacion Latinoamericana del Thorax (ALAT)

- American College of Chest Physicians (ACCP)

- American Thoracic Society (ATS)

- Asia Pacific Society of Respirology (APSR)

- European Respiratory Society (ERS)

- International Union Against Tuberculosis and Lung Disease (The Union)

- Pan African Thoracic Society (PATS)

investment in basic, clinical and translational research worldwide. It is safe to say that WSD has truly helped to meet these aims!

\section{Famous faces}

WSD was supported by famous faces in different countries. In Portugal, international footballer Cristiano Ronaldo headed up the campaign and supported the event. Images are shown here of the lorries carrying his picture, which are set to tour Portugal for the next month.

In Norway, the Mayor of Oslo and one of Norway's most celebrated footballers, Martin Andresen, took spirometry tests live at the 


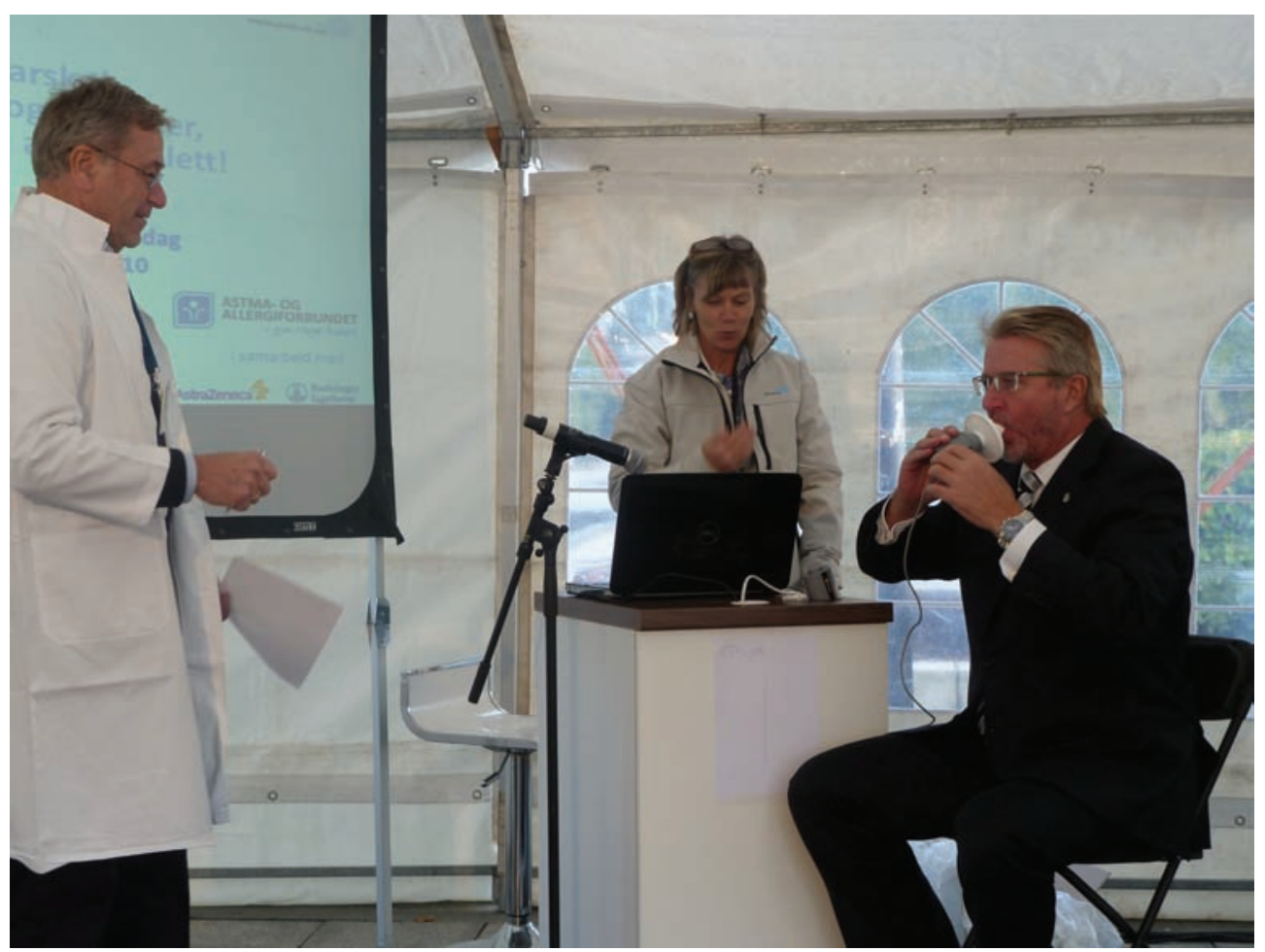

K-H. Carlsen (former ELF chair; left watches) M. Andresen (Mayor of Oslo, Norway; right) participating in his local WSD event

event in the capital city, encouraging others to do the same.

In the UK, an event at the Department of Health (London) attracted some high-level and important attention from Lord Howe (Parliamentary Under Secretary of State for Quality), Prof. Sue Hill (Chief Scientific Officer and Joint Respiratory National Clinical Director), Prof. Dame Sally Davies (Chief Medical Officer), Dr David Foster, (Deputy Chief Nursing Officer) and Karen Middleton (Chief Health Professions Officer), showing the political impact this event has had at a national level.

\section{Raising the profile of the spirometer}

Coverage about the event was impressive at a local, national and global level. To date, 183 items of press coverage of WSD have been collected and we are still asking those who held events to send in their press reports.

Examples include a piece on UK daytime TV watched by $>6,000,000$ viewers, a Moldovian TV broadcast (www.jurnaltv.com/169892/) and an article in the Wall Street Journal.
Photos of events held around the world are available on Flickr (www.flickr.com/photos/ thekkinkattil/).

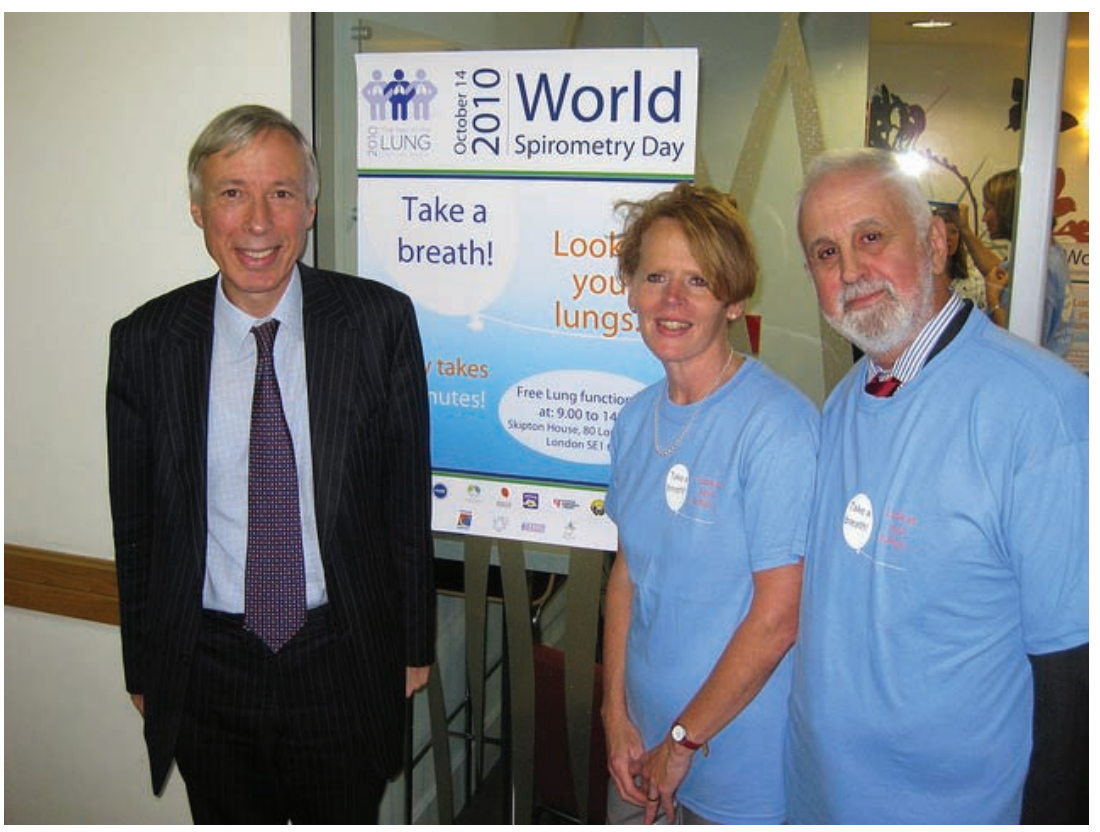

Lord Howe (Parliamentary Under Secretary of State for Quality; left) with M. Fletcher (ELF Chair; middle) and N. Siafakas (ERS Past President; right) at a WSD event at the Department of Health (London, UK) 


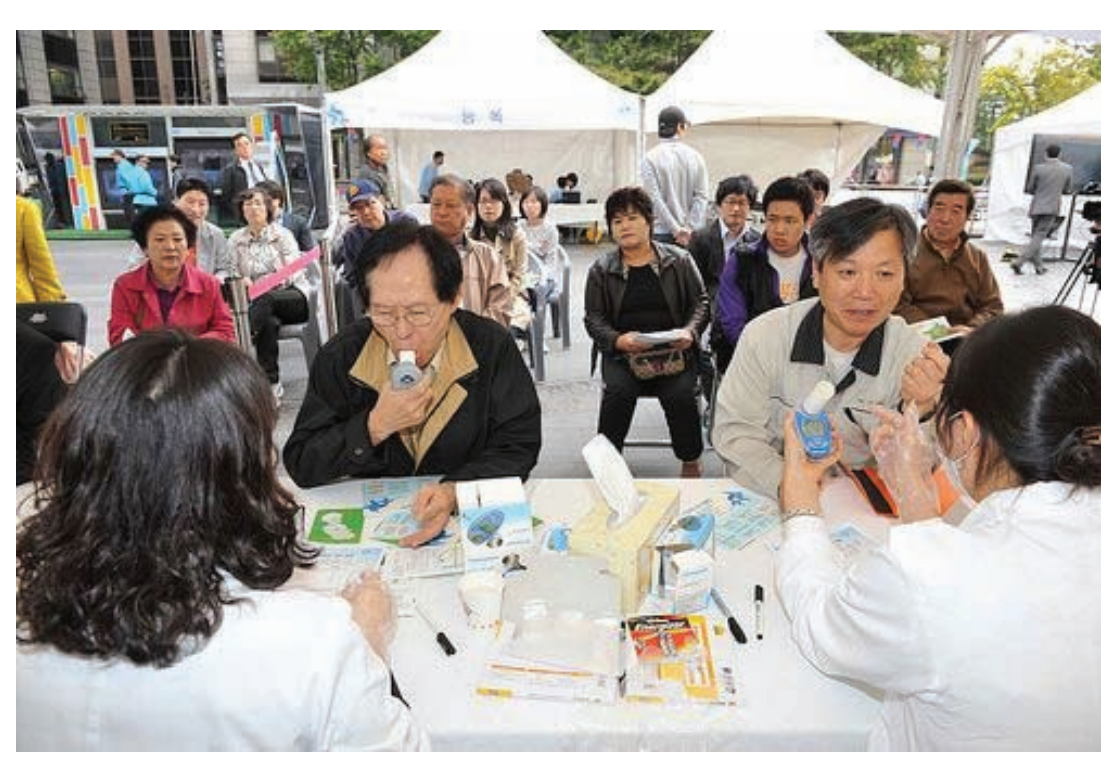

\section{What will the future bring?}

With campaigns still running, results will continue to come in. We hope to have a complete total at the end of November. Keep checking the WSD events page on the Year of the Lung website www.yearofthelung.org/wsdevents

Should WSD be a regular event? We look forward to receiving your feedback and comments for the future (elf@ersj.org.uk).

We would like to thank once more everyone who took part in WSD. Every event, large or small, helped to improve awareness of spirometry testing across the world. We thank you for your hard work and commitment.

WSD event in South Korea 